\title{
Jejunal Obstruction After Complete Transmural Gastric Band Migration
}

\author{
Florian Primavesi, MD, Tarkan Jäger, MD, Michael Baschata, MD, \\ Dietmar Öfner, MD, MAS, MSc, FACS \\ Deparment of Surgery, Paracelsus Medical University, Salzburg, Austria (all authors).
}

\begin{abstract}
Introduction: Surgery for morbid obesity is constantly gaining popularity around the world, and laparoscopic adjustable gastric banding is among the most accepted standard procedures. Lately, growing evidence for long-term complications has been reported with this particular technique. While band erosion is described in $\sim 1 \%$ of patients, complete transmural migration is scarce but may lead to acute intestinal obstruction.
\end{abstract}

Case Description: We present the case of a 55-year-old man with the rare but potentially life-threatening late complication of a complete band migration and consecutive intestinal obstruction 12 years after laparoscopic adjustable gastric banding. Intraoperative findings showed ischemic pressure ulcers and kinking of a small bowel loop due to adhesions and the migrated band device; thus, partial jejunal resection was necessary. The development of a pronounced wound infection required prolonged ambulatory wound care, but ultimately there was no permanent morbidity.

Discussion: Our report aims to raise awareness of possible long-term problems in bariatric surgery, especially after gastric banding. It demonstrates the importance of continuous supervision of obesity patients including regular assessments to avoid and detect complications even years after surgery.

Key Words: Band migration, Laparoscopic gastric banding, Long-term complications, Morbid obesity, Small-bowel obstruction.

Citation Primavesi F, Jäger T, Baschata M, Öfner D. Jejunal obstruction after complete transmural gastric band migration. CRSLS e2014.00158. DOI 10.4293/CRSLS.2014.00158

Copyright (c) 2014 SLS This is an open-access article distributed under the terms of the Creative Commons Attribution-Noncommercial-ShareAlike 3.0 Unported license, which permits unrestricted noncommercial use, distribution, and reproduction in any medium, provided the original author and source are credited.

Acknowledgment: The authors thank Anton Poggio for his kind assistance with proofreading the manuscript.

Contributions: Dr. Primavesi acquired and analyzed the patient data, wrote the manuscript, and reviewed the literature. Dr. Jäger reviewed the patient data and wrote the manuscript. Dr. Baschata wrote the manuscript, provided photographs, and reviewed the literature. Dr. Öfner reviewed the literature and wrote the manuscript

Address correspondence to: Florian Primavesi, MD, Paracelsus Medical University, Department of Surgery, Müllner Hauptstrasse 48, 5020 Salzburg, Austria. Phone: +43(0)662 4482 51002, Fax: +43(0)662 4482 51008, E-mail: f.primavesi@salk.at

\section{INTRODUCTION}

Obesity and related comorbidities such as type II diabetes and hypertension show an increasing prevalence. Several bariatric procedures have emerged, with adjustable gastric banding being a reasonably safe and widely distributed treatment for this worldwide epidemic. ${ }^{1}$ Band erosion occurs infrequently $\left(\approx 1 \%^{2-8}\right)$, whereas jejunal obstruction due to a completely migrated band device is extremely rare. To the best of our knowledge, at present there are only 3 comparable cases available by a PubMed literature search.2,9,10 We describe the case of a gastric band migration 12 years after implan- tation and 8 years after explantation of the port and catheter.

Our report details interesting intraoperative findings and emphasizes the importance of periodic assessments for patients with a history of obesity surgery to avoid and detect long-term sequelae particularly after laparoscopic gastric banding.

\section{CASE REPORT}

A 55-year-old man had received a series of surgical interventions for morbid obesity at one of our teaching hospi- 
tals that has an emphasis on bariatric surgery. With an initial body mass index of $61 \mathrm{~kg} / \mathrm{m}^{2}$, he underwent a vertical banded gastroplasty in 1989, but a stapler line insufficiency required reoperation in 1992.

After temporary weight loss to a body mass index of 50 $\mathrm{kg} / \mathrm{m}^{2}$, he started to regain weight due to recurrence of the stapler line insufficiency. Consequently, he underwent laparoscopic gastric banding with the Swedish adjustable gastric band (SAGB, Ethicon Endo-Surgery, Norderstedt, Germany) in 2000. Thereafter, his body mass index reduced to $50 \mathrm{~kg} / \mathrm{m}^{2}$ again, but he could not manage to lose any further weight.

The patient's comorbidities include high blood pressure, hypercholesterolemia, type 2 diabetes, and coronary artery disease with subacute myocardial infarction and consecutive application of a drug-eluting stent through percutaneous coronary intervention in 2009.

He was first diagnosed with a gastric band migration in 2004 when he presented to the same department with pancreatitis and consecutive upper abdominal pain. After recovery from this acute episode, endoscopic salvage by cutting and extraction of the band was attempted 1 month later but failed due to the still largely intramural position of the device. Therefore, only the port and part of the catheter were disconnected and removed under general anesthesia through a small cutaneous incision. Because the patient was asymptomatic, a timed control endoscopy within several weeks was organized, but unfortunately the patient did not keep this appointment. It was more than 2 years later when he next sought medical advice for a subcutaneous infection of the remaining catheter. This abscess was incised, and the remnant catheter was further shortened, which subsequently led to successful wound healing. The surgical department of our associated teaching hospital once more aimed for endoscopic or laparoscopic extraction of the gastric band device. However, due to the absence of symptoms, the patient again did not attend this appointment. Contrary to usual standards of care, neither further contact was induced by the other hospital nor did the patient present to another consultation independently within the following years.

In July 2012, he was readmitted to the same hospital with a sudden onset of diffuse midabdominal pain 3 hours after consumption of a meal with mushrooms. Conservative management in terms of food restriction and analgesia was initiated due to clinical and radiological signs of a small-bowel obstruction but resulted in no improvement. Despite placement of a nasogastric tube, the patient showed ongoing vomiting and abdominal discomfort, so he was finally transferred to the surgical department at our university hospital 1 day later. On admission, he was stable and afebrile with only mild pain in the periumbilical region. Symptoms were persistent even after appropriate bowel movement, so computed tomography was conducted. Computed tomography scan showed a $7-\mathrm{cm}$ mass at the ventral abdominal wall with adherent, obstructed small intestine and intraluminal position of the completely migrated gastric band device (see Figure 1).

Consequently, we opted for surgery and conducted midline laparotomy, which revealed an inflammatory mass (histologically a fat necrosis) with adherent jejunal loops (see Figures 2-4). A bowel kink at this location caused the migrated band to obstruct the intestinal lumen with residual food remnants, including the previously mentioned mushrooms, acting as a bezoar. This resulted in ischemic damage to the bowel wall (pressure ulcers); thus, partial jejunum resection was necessary.

Intraoperative gastroscopy confirmed the insufficient stapler line after vertical banded gastroplasty but showed no signs of residual ulcers or perforations in the former area of the gastric banding. This supports our theory that total band migration must have occurred long before this acute episode.

The early postoperative course was uneventful, until on day 6 after surgery, when the patient developed a fever due to a relatively distinct surgical site infection. This required a 5-day course of antibiotics and extended local irrigation beyond the patient's discharge, which took place on the 17 th postoperative day. Ten months later

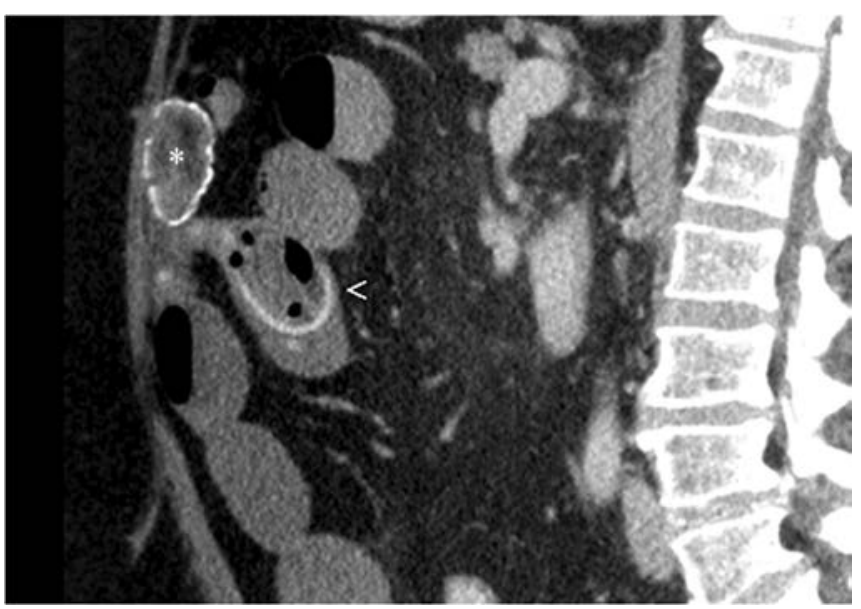

Figure 1. Computed tomography scan showing gastric banding migration into small intestine (arrowhead) adherent to a necrotic fat tissue bulk (asterisk) at the ventral abdominal wall. 


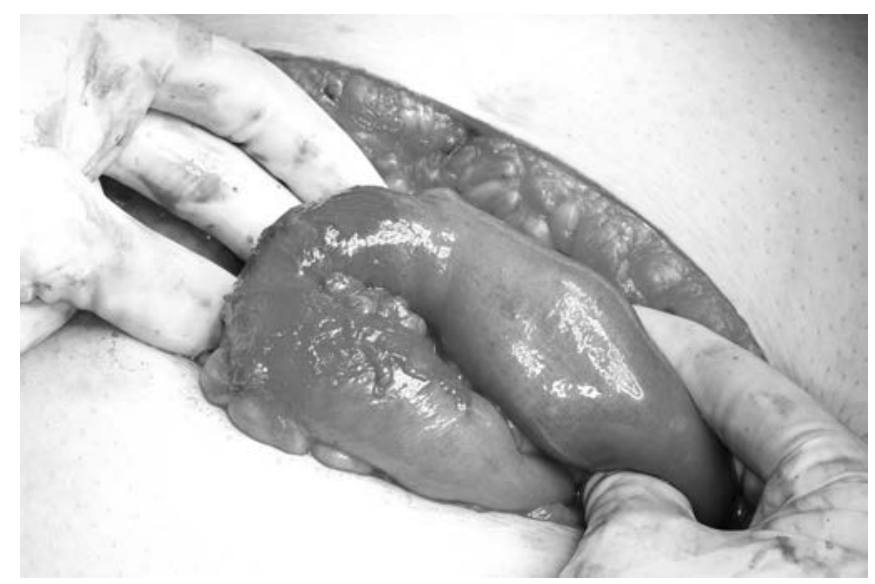

Figure 2. Obstructed small bowel loop with signs of ischemia (pressure ulcers) and palpable intraluminal migrated gastric banding.

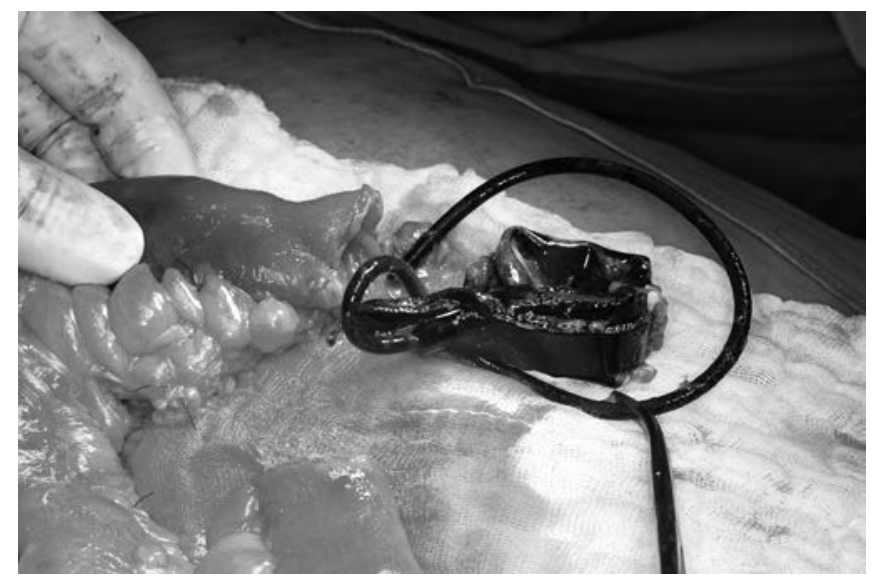

Figure 3. Extracted band device after enterotomy.

after extensive recurrent wound care at our outpatient department, including intermittent negative pressure therapy, the surgical site infection finally resolved. No further morbidity was observed.

\section{DISCUSSION}

Laparoscopic gastric banding can be an effective treatment for morbid obesity, but it shows varying popularity in different countries. Although it is considered a procedure with a reasonable surgical risk in terms of short-term morbidity, there is growing evidence for rather frequent long-term problems and a higher failure rate concerning successful weight loss when compared with more invasive procedures such as Roux-en-Y gastric bypass or sleeve gastrectomy. ${ }^{11-13}$

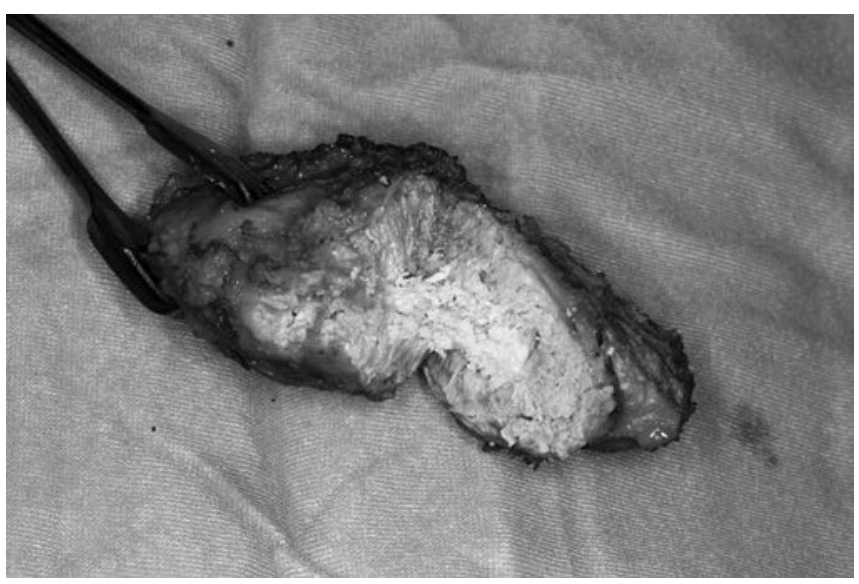

Figure 4. Resected fat necrosis located at the ventral abdominal wall that was causing adhesions.

During surgery, the band is placed around the proximal part of the stomach and connected to a subcutaneous reservoir via a catheter. ${ }^{14}$ Adjusting the diameter of the gastric band by inflating or deflating this port through direct percutaneous puncture changes the passable width for ingested food. ${ }^{15}$ This aims for individual postoperative adaptation and optimal weight loss while avoiding side effects. Regular ambulatory assessments at specialized obesity clinics, implying contrast studies, are important to avoid complications and achieve reasonable restriction without obstruction while maintaining an appropriate level of patient comfort. ${ }^{15}$ In this regard, a bariatric surgery patient's compliance and follow-up adherence is not only an important risk factor for insufficient weight loss and increased morbidity, but it also shows great variability. ${ }^{16,17}$ This sometimes evokes potentially serious problems, as seen in our case.

Possible postoperative risks include both short- and longterm complications such as pouch and esophagus dilatation, ongoing vomiting, acid reflux, and lack of weight loss, as well as gastric banding migration. The incidence of the latter is described as $\approx 1 \%$ in several studies, ${ }^{2-8}$ but the mechanisms of erosion and migration are not entirely clarified. Several investigators ${ }^{8}$ suggest that either intraoperative events such as cautery injuries and microperforations or (more likely) postoperative ischemia due to excessive pressure at the stomach wall provoke tissue damage. However, complete band migration with consecutive jejunal obstruction is a rare finding. Besides our report, only a few cases have been published in PubMed-listed journals so far. ${ }^{2,9,10}$ Other possible causes for gastrointestinal obstruction associated with laparoscopic gastric banding include erosion and retrograde migration to the gastroesophageal junction ${ }^{18}$ or external stenosis due to the band tubing. ${ }^{19}$ 
Uncomplicated erosion mostly is a non-life-threatening condition, and after disconnection of the port from the catheter, there are several therapeutic options, including laparoscopic ${ }^{20}$ and endoscopic salvage or the "let loose technique," 21 to await natural passage of the band itself. Whatever approach is chosen, periodic clinical assessments of the patient, including repeated conduction of $\mathrm{x}$-ray and/or endoscopy, are crucial to ensure an uncomplicated outcome..$^{15}$ In our case, the patient did not show up for any further appointments at the other hospital after disconnection of the port and catheter from the gastric banding, even though he had repeatedly received information concerning the risk of possible complications. This led to the critical situation of a complete bowel obstruction and consequently to an extensive ambulatory treatment with a high burden for the patient, as well as for the health-care system.

Progressive treatment of morbid obesity through surgical procedures, especially those such as gastric banding, may result in a more frequent appearance of rare and late complications that must be taken into consideration by everyone who deals with bariatric surgery patients. ${ }^{1}$

\section{References:}

1. Monkhouse SJ, Morgan JD, Norton SA. Complications of bariatric surgery: presentation and emergency management-a review. Ann R Coll Surg Engl. 2009;91(4):280-286.

2. Bueter M, Thalheimer A, Meyer D, Fein M. Band erosion and passage, causing small bowel obstruction. Obes Surg. 2006; 16(12):1679-1682.

3. Belachew M, Belva PH, Desaive C. Long-term results of laparoscopic adjustable gastric banding for the treatment of morbid obesity. Obes Surg. 2002;12(4):564-568.

4. Cadière GB, Himpens J, Vertruyen M, Germay O, Favretti F, Segato G. Laparoscopic gastroplasty (adjustable silicone gastric banding). Semin Laparosc Surg. 2000;7(1):55-65.

5. Dargent J. Laparoscopic adjustable gastric banding: lessons from the first 500 patients in a single institution. Obes Surg. 1999;9(5):446-452.

6. Favretti F, Cadière GB, Segato G, et al. Laparoscopic banding: selection and technique in 830 patients. Obes Surg. 2002; 12(3):385-390.

7. Chevallier JM, Zinzindohoué F, Douard R, et al. Complications after laparoscopic adjustable gastric banding for morbid obesity: experience with 1,000 patients over 7 years. Obes Surg. 2004;14(3):407-414.
8. Egberts K, Brown WA, O'Brien PE. Systematic review of erosion after laparoscopic adjustable gastric banding. Obes Surg. 2011;21(8):1272-1279.

9. Egbeare DM, Myers AF, Lawrance RJ. Small bowel obstruction secondary to intragastric erosion and migration of a gastric band. J Gastrointest Surg. 2008;12(5):983-984.

10. Lantsberg L, Kirshtein B, Leytzin A, Makarov V. Jejunal obstruction caused by migrated gastric band. Obes Surg. 2008; 18(2):225-227.

11. Tice JA, Karliner L, Walsh J, Petersen AJ, Feldman MD. Gastric banding or bypass? A systematic review comparing the two most popular bariatric procedures. Am J Med. 2008;121(10): $885-893$.

12. Zuegel NP, Lang RA, Hüttl TP, et al. Complications and outcome after laparoscopic bariatric surgery: LAGB versus LRYGB. Langenbecks Arch Surg. 2012;397(8):1235-1241.

13. Frezza EE. Laparoscopic vertical sleeve gastrectomy for morbid obesity: the future procedure of choice? Surg Today. 2007; 37(4):275-281. Epub 2007 Mar 26.

14. Bakr AA, Fahim T. Laparoscopic adjustable gastric banding is a safe and effective treatment for morbid obesity. JSLS. 1998; 2(1):57-61.

15. Ponce J, Paynter S, Fromm R. Laparoscopic adjustable gastric banding: 1,014 consecutive cases. J Am Coll Surg. 2005;201(4): $529-535$.

16. Gould JC, Beverstein G, Reinhardt S, Garren MJ. Impact of routine and long-term follow-up on weight loss after laparoscopic gastric bypass. Surg Obes Relat Dis. 2007;3(6):627-630.

17. Harper J, Madan AK, Ternovits CA, Tichansky DS. What happens to patients who do not follow-up after bariatric surgery? Am Surg. 2007;73(2):181-184.

18. Ruutiainen AT, Levine MS, Dumon K. Intraluminal erosion and retrograde migration of laparoscopic gastric band with highgrade obstruction at gastroesophageal junction. Surg Obes Relat Dis. 2012;8(2):e14-e16.

19. Van de Water W, Vogelaar FJ, Willems JM. An unusual complication 4 years after laparoscopic adjustable banding: jejunal obstruction due to the connecting tube. Obes Surg. 2011; 21(1):131-133.

20. Chousleb E, Szomstein S, Lomenzo E, et al. Laparoscopic removal of gastric band after early gastric erosion: case report and review of the literature. Surg Laparosc Endosc Percutan Tech. 2005;15(1):24-27.

21. Vasconcelos PM, Costa JP, Tavares V. Let loose technique, an option in band migration. Obes Surg. 2012;22(2):316-319. 